\title{
Mechanisms and insights into drug resistance in cancer
}

\section{Hiba Zahreddine and Katherine L. B. Borden*}

Department of Pathology and Cell Biology, Institute of Research in Immunology and Cancer, Université de Montréal, Montreal, OC, Canada

\section{Edited by:}

Gerald Batist, McGill University,

Canada

\section{Reviewed by:}

Jian Hui Wu, McGill University, Canada

Michael Witcher, McGill University, Canada

\section{*Correspondence:}

Katherine L. B. Borden, Department of Pathology and Cell Biology, Institute of Research in Immunology and Cancer, Université de Montréal, Montreal, QC, Canada H3T $1 \mathrm{J4}$

e-mail: katherine.borden@ umontreal.ca

\begin{abstract}
Cancer drug resistance continues to be a major impediment in medical oncology. Clinically, resistance can arise prior to or as a result of cancer therapy. In this review, we discuss different mechanisms adapted by cancerous cells to resist treatment, including alteration in drug transport and metabolism, mutation and amplification of drug targets, as well as genetic rewiring which can lead to impaired apoptosis. Tumor heterogeneity may also contribute to resistance, where small subpopulations of cells may acquire or stochastically already possess some of the features enabling them to emerge under selective drug pressure. Making the problem even more challenging, some of these resistance pathways lead to multidrug resistance, generating an even more difficult clinical problem to overcome. We provide examples of these mechanisms and some insights into how understanding these processes can influence the next generation of cancer therapies.
\end{abstract}

Keywords: origin of cancer, multidrug resistance, drug metabolism, drug transporters, oncogene addiction, microenvironment, collateral sensitivity, synthetic lethality

\section{CANCER TALE: ITS TREATMENT AND RELAPSE}

In 1961, Frei and Freireich initiated the high-dose four-drug combination clinical trial for the treatment of pediatric leukemia (Frei et al., 1965). Despite the threat imposed by administering four drugs at once, few weeks following treatment onset, children began to respond, "the bone marrow biopsies came back one after another-all without leukemia cells. Red blood cells and white blood cells and platelets sprouted up in an otherwise scorched field of bone marrow. But the leukemia did not return" (Mukherjee, 2010). Out of the 16 enrolled patients, 11 showed complete remission. This outstanding success, however, was short-lived. With the exception of a handful of children, all patients eventually relapsed, developing a more vigorous form of cancer that was no longer responsive to the treatment: leukemic cells had invaded the blood-brain barrier and colonized the brain "the only place unreachable by chemotherapy....the children died one after the other-felled by virtue of the adaptation designed to protect them...it was a consequence of the body's defense system subverting cancer treatment" (Mukherjee, 2010). To date, this story still reflects the same tale of cancer treatment where its resistance and relapse remains a major challenge (Wilson et al., 2009). In this review we provide an overview of advances made in our understanding of the mechanisms that enable cancerous cells to adapt to and eventually overcome therapy, and how identifying these mechanisms can help circumvent resistance and improve treatment.

Despite its complex biological nature, many recent successes have been made in the treatment of cancer, including most strikingly chronic myeloid leukemia (CML) and acute promyelocytic leukemia (APL) which have met with great success as well as many cases of pediatric leukemias, Hodgkin's lymphomas, and testicular cancers (Siegel et al., 2012). These success stories mainly relied on an increased understanding of the diverse molecular mechanisms governing tumor development. Owing to this, various anti-cancer therapies were designed to target disease-specific mechanisms that are absent in normal cells. Such strategies include (i) inhibition of a specific oncoprotein, such as targeting the oncogenic fusion proteins Bcr-Abl and PML-RARA with Gleevec and all trans retinoic acid (ATRA) with arsenic trioxide respectively or (ii) activation of a specific immune response against cancerous cells demonstrated by the use of interferon alpha alone or in combination with other anti-cancer drugs including 5-fluorouracil and cytarabine (Raderer and Scheithauer, 1995; Guilhot et al., 1997; Druker et al., 2001; Kreitman et al., 2001; Tallman et al., 2002; Goldman and Melo, 2003; O’Brien et al., 2003; Sawyers, 2004; Kreitman, 2006; Ferrantini et al., 2007; Chin and Gray, 2008; Sellers, 2011). Many of these drugs are currently being used in the clinic and have established positive impact on patient survival. However, a major impediment to their success is the development of therapeutic resistance which in some cases predates clinical intervention (Wilson et al., 2009). Based on tumor response to the initial therapy, cancer resistance can be broadly classified into two categories, primary and acquired (Meads et al., 2009; Lippert et al., 2011). While primary drug resistance exists prior to any given treatment, acquired resistance occurs after initial therapy. Unfortunately, the majority of patients will likely develop resistance at a certain point of treatment. For example, 50-70\% of patients with adenocarcinoma relapse following surgery with a chemoresistant phenotype (Castells et al., 2012), and approximately $20 \%$ of adults with acute lymphoblastic leukemia suffer from primary resistance to treatment (Testi et al., 1992; Giona et al., 1994; Thomas et al., 1999; O'Connor et al., 2011). In addition, primary resistance has been recognized in nearly 50\% of all cancer patients in the 1990s (Pinedo and Giaccone, 1998). Therefore, the design of anti-cancer drugs that are fully effective necessitates a better understanding of the mechanisms by which cancer cells elude treatment. Here we will discuss several features of drug resistant cells including modification of drug transport, mutation of extracellular receptors, amplification and mutation of drug targets as well as related topics. Additionally, we will briefly 
address the important question of how resistant cell populations emerge.

\section{MECHANISMS OF DRUG RESISTANCE}

Both primary and acquired resistance can be caused by alterations to drug metabolism (sequestrations or enhanced detoxification) or modifications to the drug targets (Gottesman, 2002; Gatti and Zunino, 2005; Teicher, 2006; Wilson et al., 2006; Ullah, 2008). A brief overview of these mechanisms supported with examples of clinical relevance are presented below (Figure 1).

Perhaps the most studied mode of resistance involves drug metabolism, including its uptake, efflux, and detoxification. The means by which drugs enter cells depend on their chemical nature, and it mainly necessitates the use of receptors, which they bind to and transmit their effects without cellular entry, or transporters, which allow their cellular entry (Gottesman, 2002). At this level, resistance can result from mutations that modify activity or reduce the expression of surface receptors and transporters. For instance, mutations or reduced expression of the extracellular receptor smoothened (Yauch et al., 2009; Atwood et al., 2012; Kasper and Toftgard, 2013), nucleoside transporters (Galmarini et al., 2001; Damaraju et al., 2003) or one or both folate transporters (Longo-Sorbello and Bertino, 2001) result in defective uptake of cyclopamine, nucleoside drugs, such as cytarabine, and toxic folate analogs, such as methotrexate, respectively. On the other hand, enhanced drug efflux is frequently caused by increased expression of ATP binding cassette (ABC) membrane transporters (Gottesman et al., 2002). Among the 48 known ABC transporters in humans, elevation of three members, P-gp (MDR1 gene product), Multidrug resistance-associated protein 1 (MRP1) and mitoxantrone resistance protein [MXR; also known as breast cancer resistance protein (BCRP) or placenta $\mathrm{ABC}$ protein $(\mathrm{ABC}$ $\mathrm{P})$ ], have been correlated with cancer chemoresistance to various drugs (Gottesman, 2002; Gottesman et al., 2002). For instance, Pgp transports a wide variety of hydrophobic anti-cancer drugs such as vinblastine, doxorubicin, vincristine, and taxol, and therefore its increased expression has been correlated with resistance to these (Gottesman et al., 2002). MRP1 on the other hand, transports negatively charged natural-product drugs in addition to drugs that have been modified by the conjugation of glutathione (GSH), glucuronic acid or sulfate (Jedlitschky et al., 1996; Hipfner et al., 1999; Konig et al., 1999; Borst et al., 2000); while, MXR overexpression has been correlated with resistance to topoisomerase I inhibitors, anthracyclines, and mitoxantrone (Gottesman, 2002). As can be seen, these factors comprise a major site for the development of drug resistance.

To exert their cytotoxic effects, many anti-cancer drugs must undergo metabolic activation. For instance, cytarabine (also known as AraC), a nucleoside drug widely used for the treatment of acute myelogenous leukemia (Sampath et al., 2006), necessitates initial phosphorylation by deoxycytidine kinase to cytarabinemonophosphate which is subsequently phosphorylated to the active form cytarabine triphosphate. To circumvent the effects of these drugs, cancer cells develop resistance through decreased drug activation (Kufe and Spriggs, 1985; Bardenheuer et al., 2005). This occurs via the downregulation or mutation of enzymes involved in this metabolic pathway, such as deoxycytidine kinase in the case of cytarabine (Sampath et al., 2006). Drug inactivation can also play a major role in the development of resistance. These mechanisms include, for example, conjugation of the drug to GSH, a powerful anti-oxidant that protects the cells against the damaging effects of reactive oxygen species (Wilson et al., 2006). GSH conjugation to platinum drugs, such as oxaliplatin and cisplatin used in the treatment of various types of cancers, renders them substrates for ABC transporters which enhances drug efflux (Meijer et al., 1992; Ishikawa and Ali-Osman, 1993). Furthermore, the topoisomerase I inhibitor, irinotecan, used for treating colon cancer, have been shown to become inactivated via phase I drug metabolizing enzymes, CYP450 (Xu and VillalonaCalero, 2002). Finally, binding of platinum drugs, particularly cisplatin, to metallothionein (MT), a small cysteine-rich protein, is another means of drug inactivation (Kelley et al., 1988; Kasahara et al., 1991).

Many cancer cells develop an overreliance or dependency on an oncogene. This is referred to as oncogene addiction (Arber et al., 1997; Weinstein, 2002; Weinstein and Joe, 2006; Sharma and Settleman, 2007). Targeting such oncogenes, provided a basis for the development of targeted therapies. Examples of such targeted therapies include: (i) imatinib targeting BCR/ABL tyrosine kinase in CML (Hughes et al., 2003), (ii) gefitinib and erlotinib targeting the epidermal growth factor receptor (EGFR) tyrosine kinase domain in non-small cell lung carcinoma (Lynch et al., 2004; Shepherd et al., 2005; Taron et al., 2005), and (iii) trastuzumab targeting human epidermal growth factor receptor-2 (HER-2) receptor in breast carcinomas (Slamon etal., 2001; Piccart-Gebhart et al., 2005). Unfortunately, the long term effectiveness of these drugs is hindered by the development of drug resistance due to mutation of the targeted protein (Gioeli, 2011; Wong and Lee, 2012). In the case of BCR/ABL and EGFR inhibitors, resistance emerges as a result of mutations occurring at the gatekeeper residues of the kinase domain which disables drug binding (Gorre et al., 2001; Blencke et al., 2003; Kobayashi et al., 2005; Pao et al., 2005; Soverini et al., 2005; Balak et al., 2006; Jabbour et al., 2006, 2008; Nicolini etal., 2006; Apperley, 2007; Costa et al., 2007; Bean et al., 2008; Gioeli, 2011). Furthermore, it has been demonstrated that resistance mutations can be detected prior to treatment in small subpopulations of tumor cells suggesting that these mutant forms were selected via the targeted therapy used (Hofmann et al., 2003; Toyooka et al., 2005; Inukai et al., 2006). In essence, understanding how mutations in the target proteins confer resistance enables the development of new therapeutic approaches to surmount resistance. For instance, second generation CML inhibitors have been developed based on mutational studies of patients who have become Gleevec resistant.

Other mechanisms by which cancerous cells circumvent the effects of targeted inhibitors have also been described, including amplification of alternative oncogenes or inactivation of alternative survival pathways (le Coutre et al., 2000; Engelman et al., 2007). In some cases, targeting of one protein alone (that cells are showing dependency on) can become ineffective because another parallel pathway supports tumor survival. In this case, the two pathways develop a synthetic lethal relationship (Hartman et al., 2001; Tucker and Fields, 2003). This way, the loss/inactivation of one of these genes would be supported by the other pathway and 


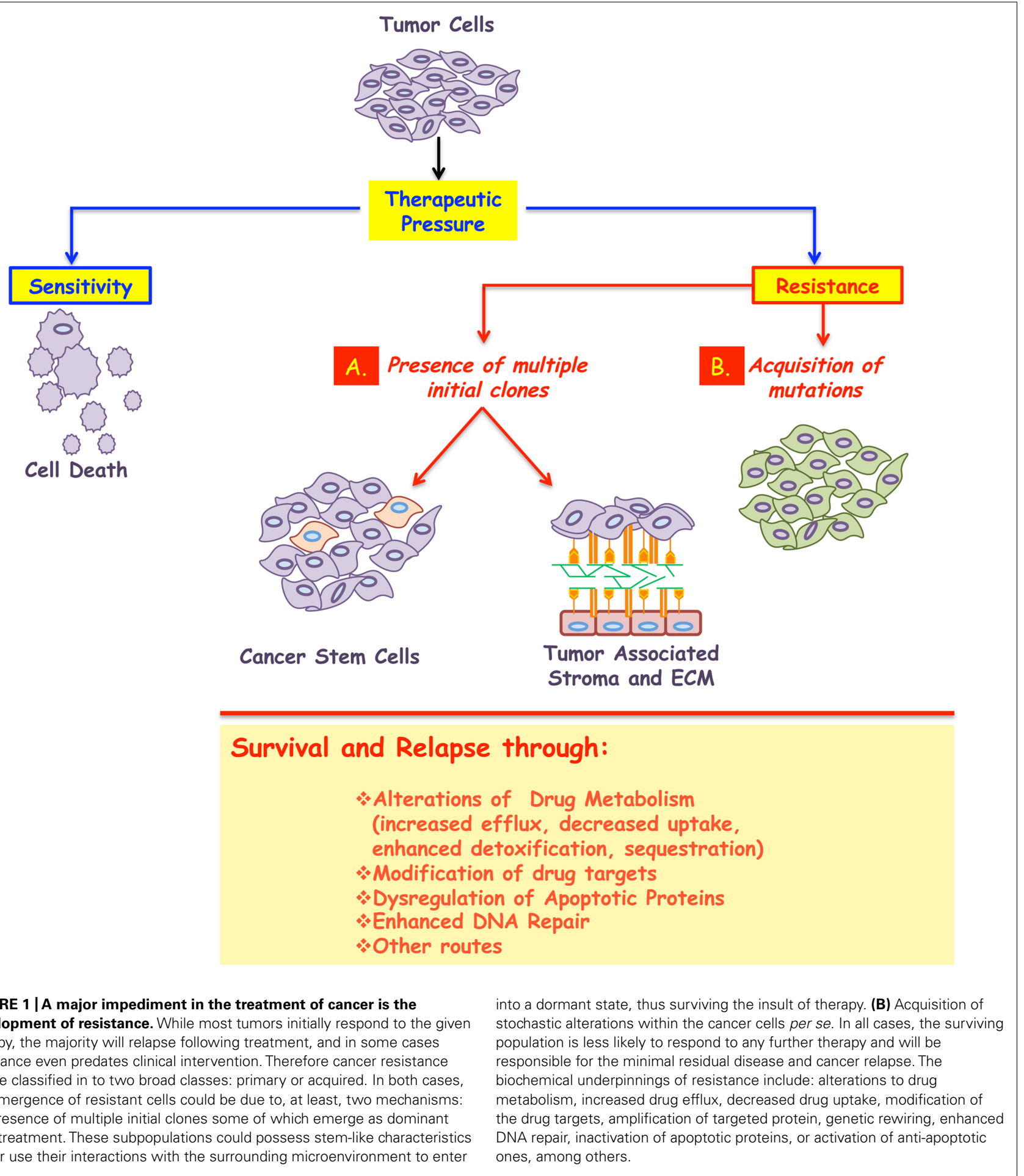

for the most effective treatment, one would need to target both pathways (Luo et al., 2009; Nijman, 2011).

An example of new pathways emerging once another pathway is targeted comes from the work of Isoyama et al. (2012), showed that acquired resistance to phosphatidylinositol 3-kinase (PI3K) inhibitors (such as ZSTK474) was due to the upregulation of insulin-like growth factor 1 receptor (IGF1R) pathway and

that inhibition of this pathway with selective IGF1R inhibitors reverses the acquired PI3Ki resistance phenotype (Isoyama et al., 2012). Additionally, resistance could result from evasion of apoptotic pathways triggered by the acquisition of either inactivating mutations in genes coding for apoptotic proteins, such as p53, or activating mutations in genes coding for anti-apoptotic proteins, such as B cell lymphoma 2 (Bcl-2; Teicher, 2006). Indeed p53 
mutations have been correlated with de novo resistance to doxorubicin treatment in patients with advanced breast cancer, as well as resistance to anthracyclines in a mouse sarcoma tumor model (Aas et al., 1996; Levine, 1997).

Another excellent example of this phenomenon (i.e., synthetic lethality) is seen in breast and ovarian cancers carrying mutations in the BRCA1 and BRCA2 genes, important mediators of DNA double-strand break (DSB) repair. When the poly (ADPribose) polymerase (PARP) protein, which is involved in different cellular processes including DNA repair, was targeted in these tumors, selective cancer cell toxicity was achieved (Bryant et al., 2005; Farmer et al., 2005). Several PARP inhibitors (PARPi) are currently being tested in clinical trials, such as iniparib (phase III ongoing; Guha, 2011) and veliparib cancer (Trudeau et al., 2006; Palma et al., 2008, 2009; Kummar et al., 2011), among others. However, despite the promising results these inhibitors showed, whether used as a mono- or combinatorial therapy (Juvekar et al., 2012; Kummar et al., 2012; Riffell et al., 2012), cancer cells once again were capable of evolving resistance to PARPi in preclinical and clinical settings (Chiarugi, 2012; Montoni et al., 2013). The mechanisms of resistance to these inhibitors have been grouped in to at least four categories, as summarized recently (Montoni et al., 2013). But perhaps the most distinct of these, was the ability of cancer cells to revert sensitivity to PARPi by acquiring deletion of the mutation in BRCA gene, thus restoring its function and the subsequent repair of DSBs.

\section{DEVELOPMENT OF CROSS RESISTANCE}

An important feature of drug resistance, is that development of resistance to one drug can lead to resistance to other drugs (Ullah, 2008). For instance, loss of a drug transporter can lead to resistance to structurally diverse compounds that utilize it or elevation of $\mathrm{ABC}$ transporters resulting from one therapy will influence the efficacy of many other compounds. Since this multidrug resistance phenotype correlates with poor chemotherapy response, drug development strategies to overcome this problem are being designed. These include drugs that are not recognized by transporters and therefore evade efflux, efflux inhibitors, drugs that are selectively lethal to P-gp expressing cells, etc. (Hall et al., 2009; Kelly et al., 2011; Nobili et al., 2012). But, perhaps resistance is not useless after all, as Hall et al. (2009) proposed. The alternative strategy to treat the progeny of the drug imposed Darwinian selection process is to identify their new "Achilles' heel," where resistance to the first given drug conferred a hypersensitivity to an alternate cytotoxic agent to which parental cells were not sensitive to. A phenomenon referred to as "collateral sensitivity", which could be considered as a type of synthetic lethality as well since the same genetic alteration that rendered the cells resistant to one drug now sensitizes them to another (Hall et al., 2009; Pluchino et al., 2012).

\section{WHERE DO RESISTANT CELLS COME FROM?}

The development of human cancers is a complex multistage process involving accumulation of both genetic and epigenetic alterations over time (Caulin and Maley, 2011). As a consequence, a single tumor is comprised of heterogeneous populations of cells with distinct genetic fingerprints (Heppner et al., 1978; Marusyk and Polyak, 2010; Michor and Polyak, 2010). As the tumor progresses, some cells undergo genetic alterations, with selection of those having a superior growth advantage in a given context. An excellent example of tumor heterogeneity is provided by breast cancer studies (Schvimer et al., 1995; Shen et al., 2000; Wild et al., 2000). Wild et al. (2000) demonstrated that about $97 \%$ of epithelial breast carcinomas possess high levels of intra-tumor diverseness. The relevance of this innate heterogeneity is seen in cancer resistance. Since cancer cell selection obeys the Darwinian law of evolution, hence, under therapeutic pressure, those populations that are most adaptive or resistant to treatment will be selected for. These clones will then dominate and populate the tumor rendering it highly resistant to the given therapy (Williams and Nesse, 1991; Nesse, 2001; Breivik, 2005; Crespi and Summers, 2005; Lichtenstein, 2005; Monceviciute-Eringiene, 2005; Greaves, 2007). The selection process can be rationalized by, at least, two mechanisms. First, the emergence of a dominant cellular population after drug selection since it possesses some favorable characteristics such as a mutated drug binding site (Zhang et al., 2006; O'Brien et al., 2007; Ricci-Vitiani et al., 2007). The second mechanism involves the acquisition of stochastic alterations within the cancer cells which provide a survival advantage (Campbell et al., 2008; Stratton et al., 2009; Negrini et al., 2010; The International Cancer Genome Consortium, 2010; Shen, 2011). The advantage itself, e.g., a mutation in a drug binding site or alteration in drug transporters (as just two examples) could be the same for either of these mechanisms. What is different is the underlying process to generate these biochemical differences.

Two known models, the cancer stem cell (CSC) model, and the environment-mediated drug resistance (EMDR) model, which are not mutually exclusive, could explain the origin of resistant cells. In the CSC model, rare populations of cancer stem cells possess tumor-initiating properties (Teicher, 2006; Nguyen et al., 2012). It is thought that CSCs diverge from normal tissue stem cells or from more-differentiated progenitor cells through dysregulation of self-renewal pathways. Beside modulation of molecular mechanisms, such as increased efficiency of DNA repair (Potten et al., 2002; Cai et al., 2004; Park and Gerson, 2005), changes in cell cycle parameters (Venezia et al., 2004), overexpression of anti-apoptotic proteins (Wang et al., 2003) or drug transporters (Gottesman et al., 2002; Krishnamurthy et al., 2004), etc., resistance of CSCs could be due to their quiescent nature (Teicher, 2006). Thus, in this case, the cell population is present and is difficult to target using traditional chemotherapy strategies many of which depend on active cell cycling.

In the EMDR model, resistance emerges as the cancer cells use their interactions with the surrounding microenvironment to enter into a quiescent or dormant state as a means of circumventing the effects of the given therapy. Under the drug imposed selection pressure, these cells remain in their protective shelter, undergoing genetic changes until they ultimately reach a more permanent acquired resistance phenotype and in turn, alter their surrounding microenvironment (Braun et al., 2000; Meads etal., 2009). These surviving populations, which may or may not be CSCs, can contribute to minimal residual disease (MRD) and cancer relapse (Matsunaga et al., 2003; Bidard et al., 2008; Meads etal., 2009). The EMDR model is relevant 
to both hematopoietic and metastatic epithelial malignancies. EMDR could be mediated by either soluble or cell adhesion-related microenvironmental factors. Soluble factor-mediated drug resistance occurs through induction of gene transcription within the tumor cells by cytokines, chemokines, or growth factors secreted by neighboring stroma-like fibroblasts (Meads et al., 2009). One of the known mediators of this resistance mechanism is interleukin-6 (IL-6), whose increased secretion has been correlated with resistance to various cytotoxins both in in vitro and in vivo models. This includes, for instance, resistance to bortezomib in multiple myeloma and to etoposide and cisplatin in hormone-independent prostate carcinomas (Borsellino et al., 1995, 1999; Frassanito et al., 2001; Voorhees et al., 2007). Further, cell adhesion-mediated drug resistance is triggered by the adhesion of integrins from tumor cells to stromal fibroblasts or to components of the surrounding extracellular matrix. Molecularly, this process could be due to many scenarios including (i) degradation of apoptotic proteins or (ii) enhanced stability or altered subcellular distribution of antiapoptotic proteins and cell cycle regulators (Hazlehurst et al., 2001, 2007; Shain et al., 2002, 2009; Lwin et al., 2007). One example is provided by studies into melphalan resistance. In this case, the cancerous cells tend to use their adhesion to fibronectin in the surrounding microenvironment to reduce the endogenous levels of the proapoptotic BH3-only Bcl-2 family member, Bim1, thus conferring resistance by disabling apoptosis (Hazlehurst et al., 2003; Hanahan and Weinberg, 2011). From a clinical point of view, it is thought that combining current therapies with inhibitors of EMDR pathways could enhance the effectiveness of the treatment (Croix et al., 1996; Weaver et al., 1997; Hazlehurst et al.,

\section{REFERENCES}

Aas, T., Borresen, A. L., Geisler, S., Smith-Sorensen, B., Johnsen, H., Varhaug, J. E., et al. (1996). Specific P53 mutations are associated with de novo resistance to doxorubicin in breast cancer patients. Nat. Med. 2, 811-814.

Apperley, J. F. (2007). Part I: mechanisms of resistance to imatinib in chronic myeloid leukaemia. Lancet Oncol. 8, 1018-1029.

Arber, N., Doki, Y., Han, E. K., Sgambato, A., Zhou, P., Kim, N. H., et al. (1997). Antisense to cyclin D1 inhibits the growth and tumorigenicity of human colon cancer cells. Cancer Res. 57, 1569-1574.

Atwood, S. X., Chang, A. L., and Oro, A. E. (2012). Hedgehog pathway inhibition and the race against tumor evolution. J. Cell Biol. 199, 193-197.

Balak, M. N., Gong, Y., Riely, G. J., Somwar, R., Li, A. R., Zakowski, M. F., et al. (2006). Novel D761Y and common secondary T790M mutations in epidermal growth factor receptor-mutant lung adenocarcinomas with acquired resistance to kinase inhibitors. Clin. Cancer Res. 12, 6494-6501.
Bardenheuer, W., Lehmberg, K., Rattmann, I., Brueckner, A., Schneider, A., Sorg, U. R., et al. (2005). Resistance to cytarabine and gemcitabine and in vitro selection of transduced cells after retroviral expression of cytidine deaminase in human hematopoietic progenitor cells. Leukemia 19, 22812288.

Bean, J., Riely, G. J., Balak, M., Marks, J. L., Ladanyi, M., Miller, V. A., et al. (2008). Acquired resistance to epidermal growth factor receptor kinase inhibitors associated with a novel T854A mutation in a patient with EGFR-mutant lung adenocarcinoma. Clin. Cancer Res. 14, 7519-7525.

Bidard, F. C., Vincent-Salomon, A., Gomme, S., Nos, C., De Rycke, Y., Thiery, J. P., et al. (2008). Disseminated tumor cells of breast cancer patients: a strong prognostic factor for distant and local relapse. Clin. Cancer Res. 14, 3306-3311.

Blencke, S., Ullrich, A., and Daub, H. (2003). Mutation of threonine 766 in the epidermal growth factor receptor reveals a hotspot for resistance formation against selective tyrosine kinase inhibitors. J. Biol. Chem. 278, 15435-15440.

2000; White et al., 2004; Lwin et al., 2007). A proof-of-principle example was demonstrated by the combination of melphalan, a DNA alkylating agent used in the treatment of multiple myeloma and ovarian carcinomas, with an anti-integrin $\alpha-4$ antibody (natalizumab) which significantly inhibited myeloma growth and reduced tumor burden in patients (Mori et al., 2004; Engelhardt and Kappos, 2008).

\section{CONCLUSION}

Resistance to drugs continues to be a major problem in oncology affecting the majority of cancer patients. Here we provide many examples of how cells become resistant to various drugs including alteration in drug metabolism, modification of drug targets, and genetic rewiring of cells to bypass targeted pathways. A better understanding of oncogene networks and oncogene cooperativity will likely improve therapeutic strategies by identifying optimal combinations based on the genetic lesions in the tumors. Importantly, tumors are highly heterogenous and this heterogeneity may well substantially contribute to primary or acquired resistance. Armed with a greater understanding of the mechanisms of drug resistance will undoubtedly lead to more long term remissions and hopefully cures.

\section{ACKNOWLEDGMENTS}

This work was supported by National Institutes for Health (NIH) and The Leukemia and Lymphoma Society (USA). Hiba Zahreddine holds a scholarship from the National Council for Scientific Research (CNRS)-Lebanon. Katherine L. B. Borden holds a Canada Research Chair.

Borsellino, N., Belldegrun, A., and Bonavida, B. (1995). Endogenous interleukin 6 is a resistance factor for cis-diamminedichloroplatinum and etoposide-mediated cytotoxicity of human prostate carcinoma cell lines. Cancer Res. 55, 4633-4639.

Borsellino, N., Bonavida, B., Ciliberto, G., Toniatti, C., Travali, S., and D’Alessandro, N. (1999). Blocking signaling through the Gp130 receptor chain by interleukin- 6 and oncostatin $\mathrm{M}$ inhibits PC-3 cell growth and sensitizes the tumor cells to etoposide and cisplatin-mediated cytotoxicity. Cancer 85, 134-144.

Borst, P., Evers, R., Kool, M., and Wijnholds, J. (2000). A family of drug transporters: the multidrug resistance-associated proteins. J. Natl. Cancer Inst. 92, 12951302.

Braun, S., Kentenich, C., Janni, W., Hepp, F., De Waal, J., Willgeroth, F, et al. (2000). Lack of effect of adjuvant chemotherapy on the elimination of single dormant tumor cells in bone marrow of high-risk breast cancer patients. J. Clin. Oncol. 18, 80-86.

Breivik, J. (2005). The evolutionary origin of genetic instability in cancer development. Semin. Cancer Biol. 15, 51-60.

Bryant, H. E., Schultz, N., Thomas, H. D., Parker, K. M., Flower, D., Lopez, E., et al. (2005). Specific killing of BRCA2-deficient tumours with inhibitors of poly(ADP-ribose) polymerase. Nature 434, 913-917.

Cai, J., Weiss, M. L., and Rao, M. S. (2004). In search of "stemness". Exp. Hematol. 32, 585-598.

Campbell, P. J., Stephens, P. J., Pleasance, E. D., O'Meara, S., Li, H., Santarius, T., et al. (2008). Identification of somatically acquired rearrangements in cancer using genome-wide massively parallel paired-end sequencing. Nat. Genet. 40, 722-729.

Castells, M., Thibault, B., Delord, J. P., and Couderc, B. (2012). Implication of tumor microenvironment in chemoresistance: tumor-associated stromal cells protect tumor cells from cell death. Int. J. Mol. Sci. 13, 95459571.

Caulin, A. F., and Maley, C. C. (2011). Peto's Paradox: evolution's prescription for cancer prevention. Trends Ecol. Evol. 26, 175-182.

Chiarugi, A. (2012). A snapshot of chemoresistance to PARP inhibitors. Trends Pharmacol. Sci. 33, 42-48. 
Chin, L., and Gray, J. W. (2008). Translating insights from the cancer genome into clinical practice. Nature 452, 553-563.

Costa, D. B., Halmos, B., Kumar, A., Schumer, S. T., Huberman, M. S., Boggon, T. J., et al. (2007). BIM mediates EGFR tyrosine kinase inhibitorinduced apoptosis in lung cancers with oncogenic EGFR mutations. PLoS Med. 4:e315. doi: 10.1371/journal.pmed.0040315

Crespi, B., and Summers, K. (2005). Evolutionary biology of cancer. Trends Ecol. Evol. 20, 545-552.

Croix, B. S., Rak, J. W., Kapitain, S., Sheehan, C., Graham, C. H., and Kerbel, R. S. (1996). Reversal by hyaluronidase of adhesiondependent multicellular drug resistance in mammary carcinoma cells. J. Natl. Cancer Inst. 88, 1285 1296.

Damaraju, V. L., Damaraju, S., Young, J. D., Baldwin, S. A., Mackey, J., Sawyer, M. B., et al. (2003). Nucleoside anticancer drugs: the role of nucleoside transporters in resistance to cancer chemotherapy. Oncogene 22, 7524-7536

Druker, B. J., Talpaz, M., Resta, D. J., Peng, B., Buchdunger, E., Ford, J. M., etal. (2001). Efficacy and safety of a specific inhibitor of the BCR-ABL tyrosine kinase in chronic myeloid leukemia. N. Engl. J. Med. 344, 1031-1037.

Engelhardt, B., and Kappos, L. (2008). Natalizumab: targeting alpha4integrins in multiple sclerosis. Neurodegener. Dis. 5, 16-22.

Engelman, J. A., Zejnullahu, K., Mitsudomi, T., Song, Y., Hyland, C., Park, J. O., et al. (2007). MET amplification leads to gefitinib resistance in lung cancer by activating ERBB3 signaling. Science 316, 1039-1043.

Farmer, H., Mccabe, N., Lord, C. J., Tutt, A. N., Johnson, D. A., Richardson, T. B., et al. (2005). Targeting the DNA repair defect in BRCA mutant cells as a therapeutic strategy. Nature 434 917-921.

Ferrantini, M., Capone, I., and Belardelli, F. (2007). Interferon-alpha and cancer: mechanisms of action and new perspectives of clinical use. Biochimie 89, 884-893.

Frassanito, M. A., Cusmai, A., Iodice, G. and Dammacco, F. (2001). Autocrine interleukin- 6 production and highly malignant multiple myeloma: relation with resistance to drug-induced apoptosis. Blood 97, 483-489.

Frei, E. III, Karon, M., Levin, R. H., Freireich, E. J., Taylor, R. J., Hananian, J., et al. (1965). The effectiveness of combinations of antileukemic agents in inducing and maintaining remission in children with acute leukemia. Blood 26, 642-656.

Galmarini, C. M., Mackey, J. R. and Dumontet, C. (2001). Nucleoside analogues: mechanisms of drug resistance and reversal strategies. Leukemia 15, 875-890.

Gatti, L., and Zunino, F. (2005). Overview of tumor cell chemoresistance mechanisms. Methods Mol. Med. 111, 127-148.

Gioeli, D. (2011). Targeted Therapies Mechanisms of Resistance. New York: Humana Press.

Giona, F., Testi, A. M., Annino, L., Amadori, S., Arcese, W., Camera, A., et al. (1994). Treatment of primary refractory and relapsed acute lymphoblastic leukaemia in children and adults: the GIMEMA/AIEOP experience. Gruppo Italiano Malattie Ematologiche Maligne dell'Adulto. Associazione Italiana Ematologia ed Ocologia Pediatrica. Br. J. Haematol. 86, 55-61.

Goldman, J. M., and Melo, J. V. (2003). Chronic myeloid leukemia - advances in biology and new approaches to treatment. N. Engl. J. Med. 349, 1451-1464.

Gorre, M. E., Mohammed, M., Ellwood, K., Hsu, N., Paquette, R., Rao, P. N., et al. (2001). Clinical resistance to STI-571 cancer therapy caused by BCR-ABL gene mutation or amplification. Science 293, 876-880.

Gottesman, M. M. (2002). Mechanisms of cancer drug resistance. Annu. Rev. Med. 53, 615-627.

Gottesman, M. M., Fojo, T., and Bates, S. E. (2002). Multidrug resistance in cancer: role of ATP-dependent transporters. Nat. Rev. Cancer 2, 48-58.

Greaves, M. (2007). Darwinian medicine: a case for cancer. Nat. Rev. Cancer 7, 213-221.

Guha, M. (2011). PARP inhibitors stumble in breast cancer. Nat. Biotechnol. 29, 373-374.

Guilhot, F., Chastang, C., Michallet, M., Guerci, A., Harousseau, J. L., Maloisel, F., et al. (1997). Interferon alfa$2 \mathrm{~b}$ combined with cytarabine versus interferon alone in chronic myelogenous leukemia. French Chronic Myeloid Leukemia Study Group. N Engl. J. Med. 337, 223-229.

Hall, M. D., Handley, M. D., and Gottesman, M. M. (2009). Is resistance useless? Multidrug resistance and collateral sensitivity. Trends Pharmacol. Sci. 30, 546-556.

Hanahan, D., and Weinberg, R. A. (2011). Hallmarks of cancer: the next generation. Cell 144, 646-674.

Hartman, J. L. T., Garvik, B., and Hartwell, L. (2001). Principles for the buffering of genetic variation. Science 291, 1001-1004.

Hazlehurst, L. A., Argilagos, R. F., and Dalton, W. S. (2007). Betal integrin mediated adhesion increases Bim protein degradation and contributes to drug resistance in leukaemia cells. Br. J. Haematol. 136, 269-275.

Hazlehurst, L. A., Damiano, J. S., Buyuksal, I., Pledger, W. J., and Dalton, W. S. (2000). Adhesion to fibronectin via betal integrins regulates $\mathrm{p} 27 \mathrm{kip}$ levels and contributes to cell adhesion mediated drug resistance (CAMDR). Oncogene 19, 4319-4327.

Hazlehurst, L. A., Enkemann, S. A., Beam, C. A., Argilagos, R. F., Painter, J., Shain, K. H., et al. (2003). Genotypic and phenotypic comparison of de novo and acquired melphalan resistance in an isogenic multiple myeloma cell line model. Cancer Res. 63, 7900-7906.

Hazlehurst, L. A., Valkov, N., Wisner, L., Storey, J. A., Boulware, D., Sullivan, D. M., et al. (2001). Reduction in drug-induced DNA double-strand breaks associated with betal integrinmediated adhesion correlates with drug resistance in U937 cells. Blood 98, 1897-1903.

Heppner, G. H., Dexter, D. L., Denucci, T., Miller, F. R., and Calabresi, P. (1978). Heterogeneity in drug sensitivity among tumor cell subpopulations of a single mammary tumor. Cancer Res. 38, 3758-3763.

Hipfner, D. R., Deeley, R. G., and Cole, S. P. (1999). Structural, mechanistic and clinical aspects of MRP1. Biochim. Biophys. Acta 1461, 359-376.

Hofmann, W. K., Komor, M., Wassmann, B., Jones, L. C., Gschaidmeier, H., Hoelzer, D., et al. (2003). Presence of the BCR-ABL mutation Glu255Lys prior to STI571 (imatinib) treatment in patients with $\mathrm{Ph}+$ acute lymphoblastic leukemia. Blood 102, 659-661.

Hughes, T. P., Kaeda, J., Branford, S., Rudzki, Z., Hochhaus, A., Hensley, M. L., etal. (2003). Frequency of major molecular responses to imatinib or interferon alfa plus cytarabine in newly diagnosed chronic myeloid leukemia. N. Engl. J. Med. 349, 1423-1432.

Inukai, M., Toyooka, S., Ito, S., Asano, H., Ichihara, S., Soh, J., et al. (2006) Presence of epidermal growth factor receptor gene $\mathrm{T} 790 \mathrm{M}$ mutation as a minor clone in non-small cell lung cancer. Cancer Res. 66, 7854-7858.

Ishikawa, T., and Ali-Osman, F. (1993). Glutathione-associated cis-diamminedichloroplatinum(II) metabolism and ATP-dependent efflux from leukemia cells. Molecular characterization of glutathioneplatinum complex and its biological significance. J. Biol. Chem. 268, 20116-20125.

Isoyama, S., Dan, S., Nishimura, Y., Nakamura, N., Kajiwara, G., Seki, M., et al. (2012). Establishment of phosphatidylinositol 3-kinase inhibitorresistant cancer cell lines and therapeutic strategies for overcoming the resistance. Cancer Sci. 103, 19551960.

Jabbour, E., Kantarjian, H., Jones, D., Breeden, M., Garcia-Manero, G., O'Brien, S., et al. (2008). Characteristics and outcomes of patients with chronic myeloid leukemia and T315I mutation following failure of imatinib mesylate therapy. Blood 112, 53-55.

Jabbour, E., Kantarjian, H., Jones, D., Talpaz, M., Bekele, N., O’Brien, S., et al. (2006). Frequency and clinical significance of BCR-ABL mutations in patients with chronic myeloid leukemia treated with imatinib mesylate. Leukemia 20, 1767-1773.

Jedlitschky, G., Leier, I., Buchholz, U., Barnouin, K., Kurz, G., and Keppler, D. (1996). Transport of glutathione, glucuronate, and sulfate conjugates by the MRP gene-encoded conjugate export pump. Cancer Res. 56, 988-994.

Juvekar, A., Burga, L. N., Hu, H., Lunsford, E. P., Ibrahim, Y. H., Balmana, J., etal. (2012). Combining a PI3K inhibitor with a PARP inhibitor provides an effective therapy for BRCA1-related breast cancer. Cancer Discov. 2, 1048-1063.

Kasahara, K., Fujiwara, Y., Nishio, K., Ohmori, T., Sugimoto, Y., Komiya, K., et al. (1991). Metallothionein content correlates with the sensitivity of human small cell lung cancer cell lines to cisplatin. Cancer Res. 51, 3237-3242.

Kasper, M., and Toftgard, R. (2013). Smoothing out drug resistance. Cancer Cell 23, 3-5.

Kelley, S. L., Basu, A., Teicher, B. A., Hacker, M. P., Hamer, D. H., and Lazo, J. S. (1988). Overexpression of metallothionein confers resistance to anticancer drugs. Science 241, 18131815.

Kelly, R. J., Draper, D., Chen, C. C., Robey, R. W., Figg, W. D., Piekarz, R. L., et al. (2011). A pharmacodynamic study of docetaxel in combination with the P-glycoprotein antagonist tariquidar (XR9576) in patients with lung, ovarian, and cervical cancer. Clin. Cancer Res. 17, 569-580.

Kobayashi, S., Boggon, T. J., Dayaram, T., Janne, P. A., Kocher, O., Meyerson, M., et al. (2005). EGFR mutation and 
resistance of non-small-cell lung cancer to gefitinib. N. Engl. J. Med. 352, 786-792.

Konig, J., Nies, A. T., Cui, Y., Leier, I., and Keppler, D. (1999). Conjugate export pumps of the multidrug resistance protein (MRP) family: localization, substrate specificity, and MRP2-mediated drug resistance. Biochim. Biophys. Acta 1461, 377-394.

Kreitman, R. J. (2006). Immunotoxins for targeted cancer therapy. AAPS J. 8, E532-E551.

Kreitman, R. J., Wilson, W. H., Bergeron, K., Raggio, M., StetlerStevenson, M., Fitzgerald, D. J., et al. (2001). Efficacy of the anti-CD22 recombinant immunotoxin BL22 in chemotherapy-resistant hairy-cell leukemia. N. Engl. J. Med. 345, 241-247.

Krishnamurthy, P., Ross, D. D., Nakanishi, T., Bailey-Dell, K., Zhou, S., Mercer, K. E., et al. (2004). The stem cell marker Bcrp/ABCG2 enhances hypoxic cell survival through interactions with heme. J. Biol. Chem. 279, 24218-24225.

Kufe, D. W., and Spriggs, D. R. (1985). Biochemical and cellular pharmacology of cytosine arabinoside. Semin. Oncol. 12, 34-48.

Kummar, S., Chen, A., Ji, J., Zhang, Y., Reid, J. M., Ames, M., et al. (2011). Phase I study of PARP inhibitor ABT888 in combination with topotecan in adults with refractory solid tumors and lymphomas. Cancer Res. 71, 5626-5634.

Kummar, S., Chen, A., Parchment, R. E., Kinders, R. J., Ji, J., Tomaszewski, J. E., et al. (2012). Advances in using PARP inhibitors to treat cancer. $B M C \mathrm{Med}$. 10:25. doi: 10.1186/1741-7015-10-25

le Coutre, P., Tassi, E., Varella-Garcia, M., Barni, R., Mologni, L., Cabrita, G., et al. (2000). Induction of resistance to the Abelson inhibitor STI571 in human leukemic cells through gene amplification. Blood 95, 17581766.

Levine, A. J. (1997). p53, the cellular gatekeeper for growth and division. Cell 88, 323-331.

Lichtenstein, A. V. (2005). On evolutionary origin of cancer. Cancer Cell Int. 5, 5 .

Lippert, T. H., Ruoff, H. J., and Volm, M. (2011). Current status of methods to assess cancer drug resistance. Int. J. Med. Sci. 8, 245-253.

Longo-Sorbello, G. S., and Bertino, J. R. (2001). Current understanding of methotrexate pharmacology and efficacy in acute leukemias. Use of newer antifolates in clinical trials. Haematologica 86, 121-127.
Luo, J., Solimini, N. L., and Elledge, S. J. (2009). Principles of cancer therapy: oncogene and non-oncogene addiction. Cell 136, 823-837.

Lwin, T., Hazlehurst, L. A., Dessureault, S., Lai, R., Bai, W., Sotomayor, E. et al. (2007). Cell adhesion induces p27Kip1-associated cell-cycle arrest through down-regulation of the SCFSkp2 ubiquitin ligase pathway in mantle-cell and other non-Hodgkin B-cell lymphomas. Blood 110, 16311638.

Lynch, T. J., Bell, D. W., Sordella, R. Gurubhagavatula, S., Okimoto, R. A., Brannigan, B. W., et al. (2004). Activating mutations in the epidermal growth factor receptor underlying responsiveness of non-small-cell lung cancer to gefitinib. N. Engl. J. Med. 350, 2129-2139.

Marusyk, A., and Polyak, K. (2010). Tumor heterogeneity: causes and consequences. Biochim. Biophys. Acta 1805, 105-117.

Matsunaga, T., Takemoto, N., Sato, T., Takimoto, R., Tanaka, I., Fujimi, A., et al. (2003). Interaction between leukemic-cell VLA-4 and stromal fibronectin is a decisive factor for minimal residual disease of acute myelogenous leukemia. Nat. Med. 9 , 1158-1165.

Meads, M. B., Gatenby, R. A., and Dalton, W. S. (2009). Environmentmediated drug resistance: a major contributor to minimal residual disease. Nat. Rev. Cancer 9, 665-674.

Meijer, C., Mulder, N. H., TimmerBosscha, H., Sluiter, W. J., Meersma, G. J., and De Vries, E. G. (1992) Relationship of cellular glutathione to the cytotoxicity and resistance of seven platinum compounds. Cancer Res. 52, 6885-6889.

Michor, F., and Polyak, K. (2010). The origins and implications of intratumor heterogeneity. Cancer Prev. Res. (Phila) 3, 1361-1364.

Monceviciute-Eringiene, E. (2005). Neoplastic growth: the consequence of evolutionary malignant resistance to chronic damage for survival of cells (review of a new theory of the origin of cancer). Med. Hypotheses 65, 595-604.

Montoni, A., Robu, M., Pouliot, E., and Shah, G. M. (2013). Resistance to PARP-inhibitors in Cancer Therapy. Front. Pharmacol. 4:18. doi: 10.3389/fphar.2013.00018

Mori, Y., Shimizu, N., Dallas, M. Niewolna, M., Story, B., Williams, P. J., et al. (2004). Anti-alpha4 integrin antibody suppresses the development of multiple myeloma and associated osteoclastic osteolysis. Blood 104, 2149-2154.
Mukherjee, S. (2010). The Emperor of All Maladies: a Biography of Cancer. New York: Scribner.

Negrini, S., Gorgoulis, V. G., and Halazonetis, T. D. (2010). Genomic instability - an evolving hallmark of cancer. Nat. Rev. Mol. Cell Biol. 11 220-228.

Nesse, R. M. (2001). How is Darwinian medicine useful? West. J. Med. 174, 358-360.

Nguyen, L. V., Vanner, R., Dirks, P., and Eaves, C. J. (2012). Cancer stem cells: an evolving concept. Nat. Rev. Cancer 12, 133-143.

Nicolini, F. E., Corm, S., Le, Q. H., Sorel, N., Hayette, S., Bories, D., etal. (2006). Mutation status and clinical outcome of 89 imatinib mesylate-resistant chronic myelogenous leukemia patients: a retrospective analysis from the French intergroup of CML (Fi(phi)-LMC GROUP). Leukemia 20, 1061-1066.

Nijman, S. M. (2011). Synthetic lethality: general principles, utility and detection using genetic screens in human cells. FEBS Lett. 585, 1-6.

Nobili, S., Landini, I., Mazzei, T., and Mini, E. (2012). Overcoming tumo multidrug resistance using drugs able to evade P-glycoprotein or to exploit its expression. Med. Res. Rev. 32, 1220-1262.

O’Brien, C. A., Pollett, A., Gallinger, S., and Dick, J. E. (2007). A human colon cancer cell capable of initiating tumour growth in immunodeficient mice. Nature 445, 106-110.

O’Brien, S. G., Guilhot, F., Larson, R. A., Gathmann, I., Baccarani, M. Cervantes, F., et al. (2003). Imatinib compared with interferon and low-dose cytarabine for newly diagnosed chronic-phase chronic myeloid leukemia. N. Engl. J. Med. 348, 994 1004.

O’Connor, D., Sibson, K., Caswell, M., Connor, P., Cummins, M., Mitchell, C., et al. (2011). Early UK experience in the use of clofarabine in the treatment of relapsed and refractory paediatric acute lymphoblastic leukaemia. Br. J. Haematol. 154, 482-485.

Palma, J. P., Rodriguez, L. E., Bontcheva-Diaz, V. D., Bouska, J. J., Bukofzer, G., Colon-Lopez, M., et al. (2008). The PARP inhibitor, ABT-888 potentiates temozolomide: correlation with drug levels and reduction in PARP activity in vivo. Anticancer. Res. 28, 2625-2635.

Palma, J. P., Wang, Y. C., Rodriguez, L. E., Montgomery, D., Ellis, P. A., Bukofzer, G., et al. (2009). ABT888 confers broad in vivo activity in combination with temozolomide in diverse tumors. Clin. Cancer Res. 15, 7277-7290.

Pao, W., Miller, V. A., Politi, K. A., Riely, G. J., Somwar, R., Zakowski, M. F., et al. (2005). Acquired resistance of lung adenocarcinomas to gefitinib or erlotinib is associated with a second mutation in the EGFR kinase domain. PLoS Med. 2:e73. doi: 10.1371/journal.pmed.0020073

Park, Y., and Gerson, S. L. (2005). DNA repair defects in stem cell function and aging. Annu. Rev. Med. 56, 495-508.

Piccart-Gebhart, M. J., Procter, M., Leyland-Jones, B., Goldhirsch, A., Untch, M., Smith, I., et al. (2005). Trastuzumab after adjuvant chemotherapy in HER2-positive breast cancer. N. Engl. J. Med. 353, 1659-1672.

Pinedo, H. M., and Giaccone, G. (1998). Drug Resistance in the Treatment of Cancer. Cambridge: Cambridge University Press.

Pluchino, K. M., Hall, M. D., Goldsborough, A. S., Callaghan, R., and Gottesman, M. M. (2012). Collateral sensitivity as a strategy against cancer multidrug resistance. Drug Resist. Updat. 15, 98-105.

Potten, C. S., Owen, G., and Booth, D. (2002). Intestinal stem cells protect their genome by selective segregation of template DNA strands. J. Cell Sci. 115, 2381-2388.

Raderer, M., and Scheithauer, W. (1995). Treatment of advanced colorectal cancer with 5-fluorouracil and interferon-alpha: an overview of clinical trials. Eur. J. Cancer 31A, 1002-1008.

Ricci-Vitiani, L., Lombardi, D. G., Pilozzi, E., Biffoni, M., Todaro, M., Peschle, C., et al. (2007). Identification and expansion of human coloncancer-initiating cells. Nature 445, 111-115.

Riffell, J. L., Lord, C. J., and Ashworth, A. (2012). Tankyrase-targeted therapeutics: expanding opportunities in the PARP family. Nat. Rev. Drug Discov. 11, 923-936.

Sampath, D., Cortes, J., Estrov, Z., Du, M., Shi, Z., Andreeff, M., et al. (2006). Pharmacodynamics of cytarabine alone and in combination with 7-hydroxystaurosporine (UCN$01)$ in AML blasts in vitro and during a clinical trial. Blood 107, 2517-2524.

Sawyers, C. (2004). Targeted cancer therapy. Nature 432, 294-297.

Schvimer, M., Lash, R. H., and Katzin, W. E. (1995). Intratumoral heterogeneity of DNA ploidy in breast carcinomas: a flow cytometric assessment of sampling techniques. Cytometry 22, 292-296. 
Sellers, W. R. (2011). A blueprint for advancing genetics-based cancer therapy. Cell 147, 26-31.

Shain, K. H., Landowski, T. H., and Dalton, W. S. (2002). Adhesionmediated intracellular redistribution of c-Fas-associated death domainlike IL-1-converting enzyme-like inhibitory protein-long confers resistance to CD95-induced apoptosis in hematopoietic cancer cell lines. $J$. Immunol. 168, 2544-2553.

Shain, K. H., Yarde, D. N., Meads, M. B., Huang, M., Jove, R., Hazlehurst, L. A., et al. (2009). Betal integrin adhesion enhances IL-6-mediated STAT3 signaling in myeloma cells: implications for microenvironment influence on tumor survival and proliferation. Cancer Res. 69, 10091015

Sharma, S. V., and Settleman, J. (2007) Oncogene addiction: setting the stage for molecularly targeted cancer therapy. Genes Dev. 21, 3214-3231.

Shen, C. Y., Yu, J. C., Lo, Y. L., Kuo, C. H., Yue, C. T., Jou, Y. S., et al. (2000). Genome-wide search for loss of heterozygosity using laser capture microdissected tissue of breast carcinoma: an implication for mutator phenotype and breast cancer pathogenesis. Cancer Res. 60, 3884-3892.

Shen, Z. (2011). Genomic instability and cancer: an introduction. J. Mol Cell Biol. 3, 1-3.

Shepherd, F. A., Rodrigues Pereira, J., Ciuleanu, T., Tan, E. H., Hirsh, V., Thongprasert, S., et al. (2005). Erlotinib in previously treated nonsmall-cell lung cancer. N. Engl. J. Med. 353, 123-132.

Siegel, R., Desantis, C., Virgo, K., Stein, K., Mariotto, A., Smith, T., et al (2012). Cancer treatment and survivorship statistics, 2012. CA Cancer J. Clin. 62, 220-241.

Slamon, D. J., Leyland-Jones, B., Shak, S., Fuchs, H., Paton, V., Bajamonde, A., et al. (2001). Use of chemotherapy plus a monoclonal antibody against HER2 for metastatic breast cancer that overexpresses HER2. N. Engl. J. Med. 344, 783-792.

Soverini, S., Martinelli, G., Rosti, G., Bassi, S., Amabile, M., Poerio, A., et al. (2005). ABL mutations in late chronic phase chronic myeloid leukemia patients with up-front cytogenetic resistance to imatinib are associated with a greater likelihood of progression to blast crisis and shorter survival: a study by the GIMEMA Working Party on Chronic Myeloid Leukemia. J. Clin. Oncol. 23, 41004109.

Stratton, M. R., Campbell, P. J., and Futreal, P. A. (2009). The cancer genome. Nature 458, 719-724.

Tallman, M. S., Nabhan, C., Feusner, J. H., and Rowe, J. M. (2002). Acute promyelocytic leukemia: evolving therapeutic strategies. Blood 99, 759-767.

Taron, M., Ichinose, Y., Rosell, R., Mok, T., Massuti, B., Zamora, L., et al. (2005). Activating mutations in the tyrosine kinase domain of the epidermal growth factor receptor are associated with improved survival in gefitinib-treated chemorefractory lung adenocarcinomas. Clin. Cancer Res. 11, 5878-5885.

Teicher, B. A. (2006). Cancer Drug Resistance. Totowa: Humana Press.

Testi, A. M., Moleti, M. L., Giona, F., Iori, A. P., Meloni, G., Miniero, R., et al. (1992). Treatment of primary refractory or relapsed acute lymphoblastic leukemia (ALL) in children. Ann. Oncol. 3, 765-767.

The International Cancer Genome Consortium. (2010). International network of cancer genome projects. Nature 464, 993-998.

Thomas, D. A., Kantarjian, H., Smith, T. L., Koller, C., Cortes, J., O’Brien, S. et al. (1999). Primary refractory and relapsed adult acute lymphoblastic leukemia: characteristics, treatment results, and prognosis with salvage therapy. Cancer 86, 1216-1230.

Toyooka, S., Kiura, K., and Mitsudomi, T. (2005). EGFR mutation and response of lung cancer to gefitinib. N. Engl. J. Med. 352, 2136; author reply 2136

Trudeau, M. E., Crump, M., Charpentier, D., Yelle, L., Bordeleau, L. Matthews, S., et al. (2006). Temozolomide in metastatic breast cancer (MBC): a phase II trial of the National Cancer Institute of Canada - Clinical Trials Group (NCIC-CTG). Ann. Oncol. 17, 952-956.

Tucker, C. L., and Fields, S. (2003) Lethal combinations. Nat. Genet. 35, 204-205.
Ullah, M. F. (2008). Cancer multidrug resistance (MDR): a major impediment to effective chemotherapy. Asian Pac. J. Cancer Prev. 9, $1-6$.

Venezia, T. A., Merchant, A. A., Ramos C. A., Whitehouse, N. L., Young, A. S. Shaw, C. A., et al. (2004). Molecular signatures of proliferation and quiescence in hematopoietic stem cells. PLoS Biol. 2:e301. doi: 10.1371/journal.pbio.0020301

Voorhees, P. M., Chen, Q., Kuhn, D. J., Small, G. W., Hunsucker, S. A. Strader, J. S., et al. (2007). Inhibition of interleukin-6 signaling with CNTO 328 enhances the activity of bortezomib in preclinical models of multiple myeloma. Clin. Cancer Res. 13, 6469-6478.

Wang, S., Yang, D., and Lippman, M. E. (2003). Targeting Bcl-2 and BclXL with nonpeptidic small-molecule antagonists. Semin. Oncol. 30, 133142.

Weaver, V. M., Petersen, O. W., Wang, F., Larabell, C. A., Briand, P., Damsky, C., etal. (1997). Reversion of the malignant phenotype of human breast cells in three-dimensional culture and in vivo by integrin blocking antibodies. J. Cell Biol. 137, 231-245.

Weinstein, I. B. (2002). Cancer. Addiction to oncogenes - the Achilles heal of cancer. Science 297, 63-64.

Weinstein, I. B., and Joe, A. K. (2006) Mechanisms of disease: oncogene addiction - a rationale for molecular targeting in cancer therapy. Nat. Clin. Pract. Oncol. 3, 448-457.

White, D. E., Kurpios, N. A., Zuo, D., Hassell, J. A., Blaess, S., Mueller, U., et al. (2004). Targeted disruption of betal-integrin in a transgenic mouse model of human breast cancer reveals an essential role in mammary tumor induction. Cancer Cell 6 159-170.

Wild, P., Knuechel, R., Dietmaier, W., Hofstaedter, F., and Hartmann, A. (2000). Laser microdissection and microsatellite analyses of breast cancer reveal a high degree of tumor heterogeneity. Pathobiology 68, 180-190.

Williams, G. C., and Nesse, R. M. (1991). The dawn of Darwinian medicine. Q. Rev. Biol. 66, 1-22.
Wilson, T. R., Johnston, P. G., and Longley, D. B. (2009). Anti-apoptotic mechanisms of drug resistance in cancer. Curr. Cancer Drug Targets 9, 307-319.

Wilson, T. R., Longley, D. B., and Johnston, P. G. (2006). Chemoresistance in solid tumours. Ann. Oncol. 17(Suppl. 10), x315-x324.

Wong, A. L., and Lee, S. C. (2012). Mechanisms of resistance to trastuzumab and novel therapeutic strategies in HER2-positive breast cancer. Int. J. Breast Cancer 2012, 415170.

$\mathrm{Xu}, \mathrm{Y}$, and Villalona-Calero, M. A. (2002). Irinotecan: mechanisms of tumor resistance and novel strategies for modulating its activity. Ann. Oncol. 13, 1841-1851.

Yauch, R. L., Dijkgraaf, G. J., Alicke, B., Januario, T., Ahn, C. P., Holcomb, T., et al. (2009). Smoothened mutation confers resistance to a Hedgehog pathway inhibitor in medulloblastoma. Science 326, 572-574.

Zhang, P., Zuo, H., Ozaki, T., Nakagomi, N., and Kakudo, K. (2006). Cancer stem cell hypothesis in thyroid cancer. Pathol. Int. 56, 485-489.

Conflict of Interest Statement: The authors declare that the research was conducted in the absence of any commercial or financial relationships that could be construed as a potential conflict of interest.

Received: 31 December 2012; paper pending published: 17 January 2013; accepted: 25 February 2013; published online: 14 March 2013

Citation: Zahreddine H and Borden KLB (2013) Mechanisms and insights into drug resistance in cancer. Front. Pharmacol. 4:28. doi: 10.3389/fphar.2013.00028 This article was submitted to Frontiers in Pharmacology of Anti-Cancer Drugs, a specialty of Frontiers in Pharmacology. Copyright (c) 2013 Zahreddine and Borden. This is an open-access article distributed under the terms of the Creative Commons Attribution License, which permits use, distribution and reproduction in other forums, provided the original authors and source are credited and subject to any copyright notices concerning any third-party graphics etc. 